\title{
Elegant and Militarized: Ceremonial Volunteers and the Making of New Women Citizens in China
}

\section{KA-MING WU}

This article examines how Chinese national values are imparted to and through the recent phenomenon of ceremonial volunteers or etiquette volunteers (liyi zhiyuan). These volunteers are all young college women who serve at major national events by greeting guests, ushering, and holding ceremonial ribbons. They are supposed to embody Confucian ritual values and the practices of propriety that define China as a nation of civilization through their roles as ceremonial hostesses. This feminine symbol of national tradition and cultural virtues is realized through a heavy emphasis on discipline, physical training, compliance to authority, and collectivism expressed through the ways the performances are staged and mass mediated. This article argues that the ceremonial volunteer represents a new state effort to engineer a model woman citizen by combining the Confucian discourse on etiquette, the communist party-state discourse on militarization and strong womanhood, the communist sport tradition of body training, and the latest initiatives on volunteering. The result is the making of gendered national subjects, marking new values of class, femininity, and nationalism. This article contributes to the understanding of emergent values about gender, class, volunteering, and the important roles they play in the process of citizen making in today's China.

Keywords: China, citizen-making, etiquette training, gendered nationalism, mega events, volunteering

$I_{n}^{\mathrm{N}}$ RECENT YEARS, MANY Asian countries have seized the opportunity to show off their economic and political powers by hosting mega sport events. For example, China hosted the Olympic Games in Beijing in 2008 and the Asian Games in Guangzhou in 2010, South Korea held the Asian Games in 2013 in Incheon, and Singapore and Myanmar organized the latest two Southeast Asia Games. In these mega sport events, the narratives and images of gender figure prominently along with narratives and images of national progress, unity, regional power emergence, and economic achievements.

From flag-raising soldiers to torch-relay runners, male bodies are integral parts of major rituals in these sport events, and are seen as symbols of national power. In some of the opening ceremonies, men perform synchronized routines to demonstrate the power of male warriors while infusing militarism into the nationalist narratives and events (Kim and Choi 1997, 20). As Simon Creak $(2015,243)$ puts it, "Major sporting festivals have saturated state spectacle with muscular, athletic and at times aggressive forms of the male body." In contrast, female bodies are often associated with cultural ritual 
representations and objects of beauty. At the Laos National Games in 2000, for instance, women were dressed in traditional attire according to ethnicity as defined by the official system of national ethnic classification (243), while at the Incheon Asian Games in 2014, three hundred young women talented in playing musical instruments, singing, and dancing were sent by North Korea to serve as cheering squads. Featured in news headlines as "the army of beauty," the cheering team reinforces the role of women as custodians of traditional culture in these mega events (Reuters and Agence France-Presse 2014).

The same could be said of the presence of women in the many mega events in China, where ceremonial volunteers or Miss Etiquettes (liyi xiaojie), as they are called, appeared in the form of sweet-faced, slender-bodied, young, well-groomed, and uniformed women. At the Beijing Olympic Games, the Shanghai World Expo, and the Guangzhou Asian Games, the female ceremonial teams captured national and international attention because of their elegant manners in greeting guests; serving as ushers; and holding ceremonial ribbons, bouquets, and trays. These ceremonial hostesses are supposed to embody and demonstrate liyi (translated literally as "etiquette and ceremony"), which are Confucian values of ritual and propriety that make China "a nation of civilization." It is therefore a popular interpretation that the ceremonial volunteer is a feminine symbol of Chinese national tradition and cultural virtues.

Looking more closely at the ways these women and their training are represented in the media, however, I have found that their presence is more than just about using women's bodies to mark national cultural boundary and identity. As I will show, the etiquette classes these women are required to take consist of a lot of physical and deportment training, disciplinary exercises, and even militarized lessons. Serving as ceremonial volunteers in mega events on the one hand articulates discipline and physical training, and self-sacrifice for the collective, thus reflecting values epitomized in earlier communist discourse in the new national body. On the other hand, it is also associated with a recent state initiative that encourages citizens to be volunteers, thus highlighting the market-related values of self-actualization and self-improvement.

This essay joins ongoing discussions on the articulation of gender, nationalism, and state modernization in understanding the politics of culture and national identity (Brownell 1995; Creak 2015; Ong and Peletz 1995). In China as well as other countries, women are often construed as biological and cultural reproducers of the nation in both colonial and postcolonial contexts (Chatterjee 1986; McClintock 1995; Yuval-Davis 1997). At the same time, a nation's representation of women can be reflective of class, sexuality, and racial hierarchies within the nation (Heng and Devan 1992; Mohanty 2003; Stoler 1995). Women's bodies, sexuality, and ethnic or educational backgrounds have played pivotal roles as territorial markers, keepers of class and racial respectability, and reproducers of nations and national narratives (Kim and Choi 1997; Mosse 1998; Parker et al. 1992; Yuval-Davis 1997). Sport events, in particular, are major sites for scholars to examine the self-fashioning of national image and identity, national unity, and modernity (Joo 2012; Tomlinson and Young 2006). Existing scholarship has shown that bodily practices in mega-event rituals are key to the production of national consciousness, and even the making of the state. This essay joins these analyses to show that the staging of gender and bodies is one of the most important "strategies of substantiation" through which abstractions such as the nation and citizens are not only imaginable (Anderson 1991) but also materialized (Creak 2015, 9). 


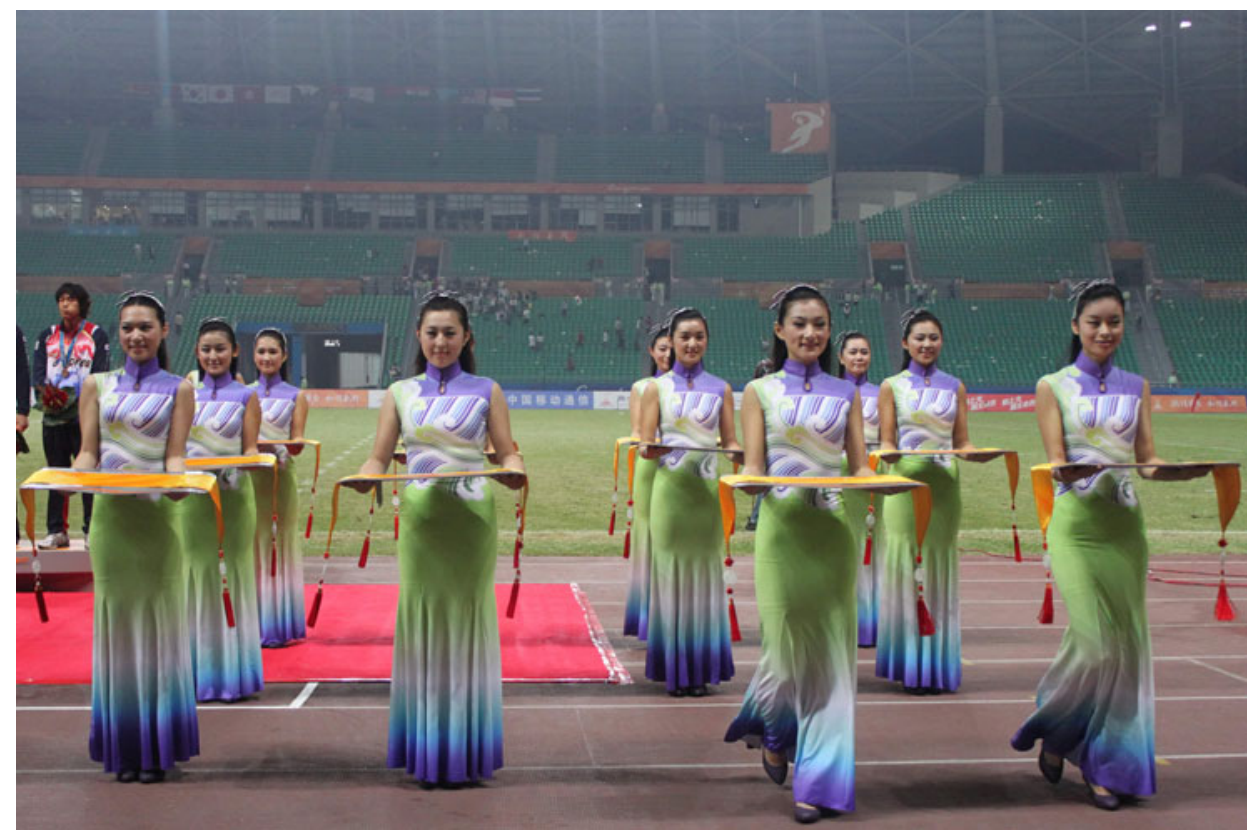

Figure 1. Ceremonial volunteers rehearsing at a venue of the Guangzhou Asian Games. Photo courtesy of Miss Wang.

The ceremonial volunteer figure represents a new state effort to engineer a model woman citizen, which highlights both discourses on and practices of traditional etiquette, military training, and volunteerism. Even though the ceremonial hostess appears to be a conventional feminine symbol of national cultural tradition, the ways she is promoted through mass media actually highlight values of discipline, physical training, compliance with authority, and collectivism (see figure 1). At the same time, the fact that these women are recruited as volunteers means that they willingly submit to the training and are proud to display these values as part of their identity. The process of training and showcasing ceremonial volunteers is the process of creating gendered citizen subjects who are proud to gain new exposure, voluntary experiences, disciplined bodies, and collectivist responsibilities. This essay contributes to the understanding of a new process of citizen making in today's China, as well as insights into the emergent values of selfimprovement, volunteering, collectivism, femininity, and class in this process.

\section{Events and Ceremonial Volunteers}

Ever since their first appearance at the Beijing Olympics in 2008, it has become commonplace to have ceremonial hostesses or Miss Etiquettes serve at events. Businesses and government departments have quickly adopted the practice of recruiting young women in feminine uniforms to appear at award presentations and official gatherings. The arrangement is now a major way to publicize and promote many big events or conventions. For instance, the National People's Congress and the Chinese People's Political Consultative Congress now deploy ceremonial hostesses to promote their annual 
meetings, prompting news headlines such as "Posture Training for the Miss Etiquette at the Two Meetings: Keep a Piece of Paper in Between Your Knees” (liyi xiaojie beizhan lianghui, shuangtui jia baizhi budiu dishang) (People.cn 2015). ${ }^{1}$ The use of ceremonial hostesses has also spilled over to academic events. It is now common to see a team of female college students serve at academic conference openings or seminars. One of the most ironic situations I encountered was when I was greeted by a group of female volunteers serving as ceremonial hostesses at a university seminar at which I was talking about the gender politics of the ceremonial hostess!

It is quite natural to subsume the phenomenon of ceremonial volunteers under an explanatory framework that sees the national deployment of feminine beauty and bodily labor as resonating with the dominant gender ideology and consumer culture, one that commodifies and sexualizes women's bodies, youth, and beauty. Women's bodies have become a large part of the beauty industry, consumerist culture, and male hegemony in today's China (M. Yang 1999). Consuming women through sex to satisfy men's so-called natural sexual desires has become part of the larger market discourse of male entrepreneurial ability and economic success (Zheng 2009). The marketplace has also become a site to display gender and class inequalities through the saleswomen's bodily and cosmetic practices directly linked to the class standing of malls and the consumption of luxury brands (Hanser 2008). Meanwhile the state plays a role in shifting gender ideology from the Maoist position, which focuses on a woman's labor, to one that focuses on a woman's body, cosmetics, and consumption (J. Yang 2011). Susan Brownell (1998), for instance, argues that the global and fashionable Chinese models on the international stage are symbolic of a Chinese state that is more patriarchal, cosmopolitan, and open-minded. In engaging these analyses, this essay shows how the figure of ceremonial volunteers complicates the gender politics described above. The ceremonial hostess is as much about showcasing a new type of woman citizen subject who is militarized and dedicated as it is about the hostess as a target of consumption. Despite the dominant understanding that the Chinese state is no longer meddling with the image of women, the state is now involving itself by juxtaposing diverse traditions of gender practices and discourses to appeal to different participants and audiences.

At the same time, my analysis engages with the recent finding of volunteering as a new form of urban governance in China, which shapes individuals into modern, responsible, and self-enterprising citizen subjects (Fleischer 2011; Hoffman 2013). Gladys Chong (2011) has argued that the Chinese state took the opportunity of the Beijing Olympic Volunteer Program to popularize the ideals of a grand China and internalize certain emotions and behaviors among its citizens. My analysis shows that volunteering is a new governing strategy the Chinese state uses to exert productive control on its citizens. But I found that volunteer governance is not simply a type of Foucauldian "technology of power," which uses productive, not repressive, means to shape citizens' bodies and behaviors. Instead, ceremonial volunteering training places a heavy emphasis on bodily discipline and strict physical lessons. It is not as decentralized and soft as often imagined. Ceremonial volunteers are required to embody, perform, and negotiate the competing discourses of China as a grand historical nation and as a modern and upwardly

${ }^{1}$ Training details are available on YouTube (see Zhongtian News 2015). 
mobile society with socialist characteristics. The gendering of contemporary state governance puts together "diverse gendered discourses" to appeal to young women (Balogun 2012). In the following sections, I discuss the process of selecting ceremonial volunteers, the details of etiquette training classes, and ceremonial volunteers' participation in the national military parade using both the media representations of these processes and in-depth interviews eliciting the volunteers' individual experiences.

I interviewed college women who have only served at mega national or international event settings as "volunteers." These female volunteers are recruited directly from colleges through the school's "communist youth league," which is a major Communist Party-sponsored social organization that specializes in youth work and political mobilization. The league arranges leaves for selected volunteers so that they can skip classes to enroll in training and serve at the games. A working committee, managed directly by the games organizing committee, arranges instructors of dance, music, art, and language to provide a forty-day training for the volunteers. Ceremonial volunteers do not receive any payment, only some meal subsidies. Every ceremonial volunteer is awarded an honor certificate after the event.

Data used in this essay comes from online and newspaper reports between 2009 and 2012 about ceremonial volunteers in the 2008 Beijing Olympics, the 2010 People's Republic of China Sixtieth Anniversary, and the 2011 Guangzhou Asian Games. In 2009, I visited the etiquette lesson of a professional modeling class in the Tianjin Polytechnic University, China, and interviewed two ceremonial volunteers responsible for holding the placards of participating countries at the Beijing Olympics Opening Ceremony. In 2010, I interviewed an additional two students from the China Women's University in Beijing who had participated in the parade for the sixtieth founding anniversary of the People's Republic of China. In 2012 and 2013, I interviewed thirteen ceremonial volunteers from a university in Guangzhou, China, who served at the Guangzhou Asian Games of 2010. I have also interviewed three main coaches involved in giving the training.

\section{The Selection of Ceremonial Volunteers}

To qualify as a ceremonial volunteer, one must go through a rigorous selection process. According to media reports, as many as 5,000 high-school and college students came to the interview site in Beijing, but only 337 got in. The basic requirements were being slender and having a "nice" face, age between eighteen and twenty-four, height between 1.65 and 1.78 meters, and being only from either Beijing and Shanghai. Right before the mega events, there were rumors that the Beijing Olympic Games Organizing Committee had a stringent aesthetic standard that dictated a specified ratio between nasal width and face length, and between mouth width and eye length. Later, a government press conference explained, "Selected women are about 168 to 170 millimeters tall, and have a friendly and amicable character, upright and balanced body figure, elegant manners, good political awareness, a spirit of giving and team work, and the will to discipline and take everyone's interests into account. The last requirement was basic English speaking and listening ability" (China.com.cn 2008). Officials explained that the body and personality specifications were meant to make sure that the selected volunteers possess “youthful, energetic, healthy and aspiring qualities.” In turn, these qualities 
would "demonstrate the good images and ambience of Chinese people's civility, etiquette, friendliness, unity and hospitality" (China.com.cn 2008). The reality was that tall and beautiful women did not automatically get in. According to my interviews, most women got in through recommendations by their college communist youth leagues, which means their political records and performance were reviewed to be sure that neither these women nor their family members had participated in any protest movements considered subversive to the government. The recruitment procedures for both the Beijing Olympic Games in 2008 and the Guangzhou Asian Games in 2010 were similar.

Those selected underwent rigorous, forty-day, closed-door training, including essential body movement protocols and strenuous etiquette sessions. The training camp was held in July and August when these young women had summer holidays and in a venue large enough to accommodate the entire group. Trainees followed a strict schedule: They woke up at six in the morning and had nine consecutive class sessions every day. These sessions covered various topics, from English oral conversation to music education to physical exercises, including smiling, posture training, walking, and standing. Some of the training sessions equipped the trainees for on-stage jobs, such as holding national placards for athlete representatives, holding medals or flowers at the award presentations, and leading VIPs into the venues. Other sessions were more about conveying a proper, cosmopolitan, and friendly image of China. Most of the sessions were widely reported and mass broadcasted on television and the Internet as a series of promotional previews of the Games.

\section{Etiquette Exercises and Military Lessons}

First, the smiling lesson. An "amiable and natural" smile is the foremost important feature of a ceremonial volunteer. The volunteer's main role is to make sure that guests always see smiling faces around. But such a smile can only come from assiduous practice. Not only must the gentle smile come across as natural, it has to live up to certain standards, specifically the quantification of exposing four to six teeth. This smiling standard, according to etiquette coaches, is to make sure that the volunteers' mouths lift upward but never open too wide. The requirement for the number of exposed teeth is to ensure the overall aesthetics of smiling. To attain this most desirable smile, the young women are taught to bite on a chopstick for hours while practicing smiling. They also giggle to themselves in front of the mirror, then to one another, face to face, correcting each other in terms of the number of teeth exposed (Lan 2008). A ceremonial volunteer who served in the 2008 Beijing Olympics told me that her perfect smile was hard earned at the cost of flowing saliva and trembling facial muscles for hours during and after training sessions. Another volunteer who served at the Guangzhou Asian Games three years later, however, said that the smile training required for them was less harsh and that the required number of exposed teeth was not as strict as in the Beijing Olympics. But both batches of trainees said they could now turn on a "natural and lasting smile" spontaneously without having to feel happy.

Second, the standing lesson. Standing posture matters a great deal in order for ceremonial volunteers to look upright and spirited, therefore effectively conveying the 
officially expected qualities of being "healthy and aspiring" (China.com.cn 2008). Media reports have covered how the trainee has to stand with her chin slightly in, a book placed on her head, and a sheet of thin paper held between her knees to attain the most ideal standing posture. Neither the book nor the sheet of paper is supposed to fall, and this is to be achieved while standing in high heels (Lan 2008). The purpose of using a sheet of paper for standing training is to make sure trainees keep their knees as close together as possible. Ceremonial volunteers told me that in the actual training one sees lots of papers falling and people not maintaining balance all the time. Young women born with very thin legs or legs bending outwards find it particularly hard to hold the paper in between their knees. The practice lasts for about one hour and may take place indoors or outdoors. Those who served at the Beijing Olympics said there were no bathroom or water breaks during the two hours of standing training. They also mentioned scenes of fellow classmates fainting after standing for too long due to poor blood circulation. However, fainting itself, they said, is not the most dreaded part; the worst is that the coach would secretly record the number of fainting episodes, which could serve as justification for that trainee's ultimate ousting from the program.

Third, the ballet body shaping (balei xingti) lesson. This is a form of posture and movement training using elements of ballet dance. In this class, trainees put on tight bodysuits and practice walking tip-toed, jumping, and stretching. The purpose of this training, according to my interviews with coaches, is to enable trainees to improve their muscle tone, sense of musical rhythm, aesthetic movement, coordination, and flexibility. All the young women I interviewed liked this session the most because it was much more fun than other posture exercises. Getting to learn a bit of ballet, which is expensive if taken at a private school, is also a bonus.

Fourthly, weight carrying. This is the most practical part of the entire training course, as ceremonial volunteers have to endure long hours of standing while holding heavy placards and trays of medals and flowers in award presentations. Each day, trainees hold metal trays, each loaded with six 500-milliliter bottles of water, for an hour. They have to do so while keeping their bodies steady. Meanwhile, constant attention has to be given to their walking pace. In the actual ceremonies, volunteers must ensure that the trays do not hit the award presenters. The specifications for how to move while carrying the trays are determined down to the centimeter. A trainee must make sure there is a fist's distance between her arm and her waist, while the thumb must not stick out beyond the tray when the tray is being carried. My interviewees complained about this part of the training because it was very tough and their arm muscles quivered badly after a day of training.

Last, military training. Toward the final phase of training, all ceremonial volunteers are sent to a military barrack in the suburbs to undergo a week (for the Guangzhou Asian Games) or two weeks (for the Beijing Olympics) of intensive training. At these trainings, trainees wake up at five every morning, make their beds according to a specific standard, and start the day with jogging. The major training elements of the day are military-style standing (zhan junzi) and marching (ti zhengbu). Military marching involves raising arms and kicking legs at right angles in a synchronized manner. When asked why military training is necessary, both the coaches and trainees believed it is to ensure obedience and improve team building. Many of them also talked of marching as improving the team's overall morale. 
Candidates have to practice all of the bodily movement protocols repeatedly during the forty days of training camp until they are performing them naturally, skillfully, and gracefully. If they are successful, they will be officially accepted as ceremonial volunteers. In general, all the exercises described are meant to help trainees attain a spirited, upright, and elegant composure. Some do not make it through all the sessions and eventually drop out. In the Beijing Olympics, some received the heart-breaking news that they were disqualified one day before the games' opening ceremony and could only serve at the much less watched Paralympics held afterwards. In the Guangzhou Asian Games, all the selected trainees made it to serving at the games' opening.

\section{Reinvention of Traditional Etiquettes}

Volunteers I interviewed said that their job is to demonstrate China as a "nation of etiquette" (liyi zhibang). By this phrase, they refer to a popular idiom of describing imperial China as a civilized nation in which people adhere to elaborate sets of Confucian ritual obligations, moral rules, and cultured behaviors. Interestingly, if one looks up the word liyi in a Chinese dictionary, its classical meaning has little to do with popular understandings of etiquette. The terms $l i$ and yi, instead, refer to systems of law and philosophy in ancient China, which govern social morality, hierarchy, proper behaviors, and social justice (see Baidu.com 2015). Philosophy scholars understand $l i$ as a site of propriety, ethical values, rules, and constraints that govern social order and cosmic process (Feng 1985, 337-39). Cultural historian Angela Zito (1995, 106) defines $l i$ as "finely differentiated practices that created a network of relationships within which situated subjectivities came into being." Respecting one's subjective position and confirming the hierarchical relations of ruler, subject, father, mother, son, and daughter, for instance, were embodied practices of $l i$. Similarly, Tani Barlow $(1995,260)$ refuses to see $l i$ as mere bodily qualities or practices, but rather as behavioral "protocols" that constitute naturalized, normative, and gendered relational subjects. Observing $l i$ is not just about practicing proper behaviors but also about acting in ways that maintain hierarchical relations such as that between mothers and sons. The staging of ceremonial volunteers to demonstrate the Confucian discourse of $l i$ is therefore a rather superficial process of translating and reinventing Chinese Confucian tradition. By calling a ceremonial volunteer "Miss Liyi," the state links women's outlook and bodily practices to a past filled with civility and rituals. However, ceremonial volunteers do not actually recreate the subject positions of virtuous women or pious daughters-in-law that the late imperial discourse of $l i$ intended to prescribe within the kin structure.

Quite ironically, the modern reenactment of etiquette practices communicates rather distinct gender and class ideologies. The college background of all selected volunteers means that only young, educated, and unmarried women are selected because they are believed to be more flexible, more civilized, and more sexually proper. Their uniform of qipao — a modern invention of traditional dress for Chinese women (Chew 2007) —as well as high heels and long hair prescribe that they move in a restrained and graceful manner. The training sessions in which they stand while keeping a piece of paper in between their legs is quite explicitly linked to proper feminine deportment and disciplined sexuality. The same goes for sitting training, which requires hostesses to close and bend their legs to the side to avoid potentially exposing their underwear. 
While the majority of women liked the ballet body-shaping lesson and thought it was fun, the female coach I interviewed in Guangzhou said that it was intended to "fix the problem of tall girls giving others an impression of domination." I did not get the chance to further inquire how ballet dancing could make women look less dominating. But the coach's words resonate with the ultimate mission of the etiquette lessons-to ensure that women walk, stand, and move to express a respectable femininity and proper sexuality associated with high-class standing and noble status. But even such a mission can be contested, as volunteers were also required to greet guests by bending their upper bodies while crossing their hands on the stomach, a posture some criticized as associated with the demeanor of household servants in premodern Chinese feudal families (Qin 2008). Most interestingly, the training, which is based on ballet dancing, a Western art form, is articulated as helping trainees to attain the so-called "Oriental beauty" (dongfangmei), understood as a form of beauty related to mystery, charisma, and pride (see Baidu.com 2017).

In the end, the performance of ceremonial volunteers conveys conflicting meanings, not just etiquette-related and ceremonial. The ceremonial hostess is simultaneously classy and deferent, modern and Oriental. She highlights concepts of class distinctiveness, instead of equality among classes. Her performance conveys the image of a nation populated no longer by the working-class masses inspired by egalitarianism but by a group of manicured women ready to show off their class respectability. She perhaps reflects the moral and cultural character of the Chinese nation today-a rapidly modernizing country eager to reinvent traditional values and gender ideology to legitimize a national cultural identity (Yan and Santos 2009). She also reveals the incongruence expressed in everyday life in Chinese society between the state narrative of upholding a proletariat dictatorship and the reality of a total embrace of wealth and status.

The female volunteers could not care less about such contradictions. Many value the training process as a way to equip themselves with etiquette knowledge and manners considered necessary in many high-ranking jobs or classy social occasions.

\section{Ceremonial Volunteers in National Military Parades}

The 2009 national military parade illustrates how the notion of etiquette is intermingled with communist party-state discourse and practices of the militarized body. As in previous national parades, the inspection of servicemen and military weapons emphasized the demonstration of military strength and the ideological outlook of the national army toward the international community. In Tiananmen Square in Beijing that day, Chinese soldiers saluted state leaders and demonstrated their adherence to military discipline by synching their movements. Their height, hair style, and the degree at which their head, neck, and eyes rotated fell into a neat pattern, without the slightest variance. Similar excellence was demonstrated at the parade by the militia women, who were selected from among qualified college-level women in Beijing. In uniform skirts and long boots, they showed the same exuberance as their male counterparts with a neat pace and consistent rhythm.

What was perhaps most eye-catching were the two captains of the marching team, Zhang Xiaofei and Zhao Na. These two women first served as ceremonial volunteers at 
the Beijing Olympic Games in 2008. After the games, they were specially selected to lead the militia women's team as captains in the grand military parade in 2009. Both women, standing at 1.78 meters and sweet-faced, were fresh Beijing university graduates who had majored in advertisement modeling and image design. News reports characterized their participation as leading "the female soldiers to go through Tiananmen Square beautifully." (Global Times 2015). I did not get the chance to interview the two volunteers and was only able to review the extensive journalistic reports on them. Interestingly, related reports were largely the same and were probably scripted by the governmentsponsored Xinhua news agency. They unanimously focused on the tough training process the two ceremonial volunteers went through, as the following excerpt shows:

Since Zhang Xiaofei and Zhao Na came to the training camp later than others, they took extra hours and made extra efforts to make up for their training. While other team members carried two pounds of sandbags, they carried four pounds. While other team members took their break, they pushed on with extra exercises; and whereas other team members held their leg up for five minutes, they would hold their leg up for fifteen minutes. "I must consider myself a male soldier," Zhang said.... Zhang's perseverance in training impressed the coach, who recalled, "One afternoon, I saw her kicking the left leg, for I don't know how many times. Eventually, her right leg couldn't hold up and was shivering badly. My tears started to run.” (Liberation Army News 2009; Wang, Yang, and Ji 2009; Xinhuanet.com 2009; author's translation)

News representations such as the above show that the ceremonial volunteer is not so much evaluated on the basis of her admirable smile or elegant postures, as she might be in the Olympic Games. In the military parade, she is evaluated on the basis of her level of perseverance in pushing through tough physical training and her ability to endure pain. Phrases like "sandbags," "holding legs up," or "kicking" present an image of the female body that is strong, even militant. The expression "I must consider myself a male soldier" reveals the identity and body after which the women volunteers modeled themselves. The male coach was so impressed with their toughness that he shed tears. Confirmation of the sought ideal came from the state party leaders after "the two ceremonial volunteers gracefully led the women militia team through the Tiananmen Rostrum," and "honorably received inspection from the party state leaders and fellow citizens of the whole nation" (He 2010).

Transforming the elegant ceremonial hostess into a militia team member is a smart state effort, strategically displayed in the national military parade. An official YouTube video version of the women's militia parade from 2009 continues to attract views today and has accumulated over 27,000 views over the years (see Xue 2009). The hostesses-turned-militia-captains invited numerous media reports and public discussions on what the militia teams were responsible for and where they came from. Newspapers ran stories on how female university students and white-collar career women seized this parade opportunity to join the female militia. It was a marketing campaign filled with enthusiasm, fantasy, and marvels, all of which-via continuous reappearances in and rebroadcasts by the news, television, and Internet media-made the military parade and related state propaganda much more interesting to follow. Once attracted by 
scenes of young and beautiful women kicking sandbags, the audience began to appreciate the perseverance and adherence to strict discipline required for all military personnel. After witnessing the physical pain the girls have to go though, perhaps they also shared the pride these girls are said to possess. In the end, it is not only the images of women militia captains that stay in the minds of the audience, but also their militarized bodies and their will to serve the nation.

The emphasis on a strong and militarized body as emblematic of a patriotic mind and nationalist commitment is not a unique phenomenon. But placing such emphasis on women as the embodiment of these ideals is a unique part of Chinese modern history. The figure of the "iron maiden" was a state-engineered role model during the Maoist period of the 1960s to 1970 s to encourage women to become physically strong and motivated to join the labor force in order to quicken the pace of national industrialization. In China, the quest for independent nationhood and modernity has been intertwined with the "woman question." Although the status of women has been interpreted in anticolonial struggles as a vital signifier of national progress and social modernization, the ways that status has been implemented are quite different in China and other Asian countries, such as India. Starting in the early 1920s, Chinese nationalist intellectuals considered many customary practices, such as arranged marriages, chastity, and bound feet, as signs of male dominance and cultural backwardness. They "identified women's oppression as symptomatic of a Confucian culture built on patriarchy" and hence considered encouraging women to participate as citizens in the public sphere a major means to uproot a Confucian feudalist culture (Seth 2013, 284).

Accordingly, when the Chinese communist state under Mao Zedong came into power in 1949, it attempted to achieve national progress and cultural modernity by encouraging the use of female labor in economic production (Gilmartin 1995; Gilmartin et al. 1994; Rofel 1999). The communist party-state invented the new subject position of "funu" after 1949 to promote the image of a woman citizen who is politically active and who places national collective interests above the interests of the family (Barlow 1995). Healthy and strong, the communist funu entered into employment that had previously been considered men's work and opposed the "ritual etiquette of the feudal society" that subjected women to suffering (276). The iron maiden was therefore a communist mobilization campaign to promote women's employment, especially in heavy industries such as coal mining, transportation, fishing, and lumber production (Jin 2006, 618). With slogans such as "women hold up half of the sky" and "times have changed-now men and women are the same," women workers in the quasi-military production farms started to engage in physically demanding jobs. The campaign eventually set off a popular social movement at the everyday production level that challenged traditional gendered divisions of labor and promoted a lifestyle of militarized principles and discipline (622). Although it was flawed in that it made male attributes the yardstick of competence, the campaign also rejected many traditional gender stereotypes. Further, it

\footnotetext{
${ }^{2}$ Sanjay Seth (2013) has brilliantly shown the divergent ways in which "tradition" is associated with feudalism and therefore has to be annihilated in China, and the ways tradition is seen as the inner, spiritual domain, and hence has to be revived and preserved in India. Seth argues that this has to do with the radically different ways colonialism figured in anti-colonial thoughts and the ways "the woman question" was signified in nationalism in each country.
} 
fought against Confucian traditions, including the discourse of $l i$, which prescribes that a proper woman's position is only within the boundaries of family. The campaign was revolutionary in that it promoted an anti-Confucian, tough, militarized, and empowering womanhood.

My informants might not share the zealously patriotic sentiment reported by Zhao $\mathrm{Na}$ and Zhang Xiaofei, and they were much more ambivalent when expressing patriotism. Nevertheless, they derived quite a lot of positive feelings from the militarized training. Feeling refreshed and stronger from the physical exercise, many of them did not consider the strict training excessive. Two of the trainees who joined the day-and-night training for the military parade in 2009 thought that the standing exercise was helpful in giving them better composure. To my surprise, many also rated the military training section positively, saying it brought forth a better team spirit. One informant, Sarah, said, "It is necessary to have the [military] training because we were too relaxed (sanman). The military standing, the slogan shouting, the marching, and the tidying exercises can help us to be more alert and serious." Another informant added, "I know that some companies also use military training in staff training to ensure the staff's obedience. I personally do not think it is necessary but I think it can help us to be more focused."

The staging of ceremonial hostesses juxtaposes the opposing traditions of gender discourses and practices. It grooms the elegant and deferent woman by reinterpreting the Confucian tradition of $l i$ while reasserting the militarized and empowered woman of the Maoist mobilization campaign at the same time. It promotes a sexually conservative image of women while also recalling a history of state mobilization that stresses women's liberation from the family domestic sphere. Most importantly, it appeals to college women who like both the classy feeling of putting on nicely tailored qipao on the grand stage of major events and the excitement of going through group military training. Both experiences are not ordinary encounters but extraordinary processes that only a select group can experience.

The juxtaposition of manner and military training defies the simplistic understanding of volunteer training as merely a form of Foucauldian technology of power that uses soft or productive techniques to control citizens' bodies. Military training is highly demanding, physical, and disciplinary. It can also be imposing and repressive. By putting ceremonial hostesses in the national military parade, the state has found an effective articulation of the traditional discourse of etiquette with the state practice of converting civilian bodies to military and nation-serving principles. Increasingly, etiquette training is understood in terms of not only grooming nice manners but also discipline and dedication. Zhang Xiaofei and Zhao Na's effectiveness as leaders in the militia women's parade lies not in their elegant manners, but in the way their military training has proven their perseverance, obedience, and ability to attain "the demeanor of a socialist person, which is making oneself as a vehicle of the collective interests, "a model of an exemplary citizen who stands in complete subordination in front of the leadership" (Roubal 2003, 7). Indeed, the discourse of etiquette in today's China is increasingly articulated with bodily discipline and an expression of the collective.

Lastly, the more I asked about the bodily disciplines required of ceremonial volunteers, the more I found that they are part and parcel of a much more general disciplinary form required of young Chinese citizens in many other sports, events, or everyday activities. One of these activities is the military training camp compulsory for college freshmen 


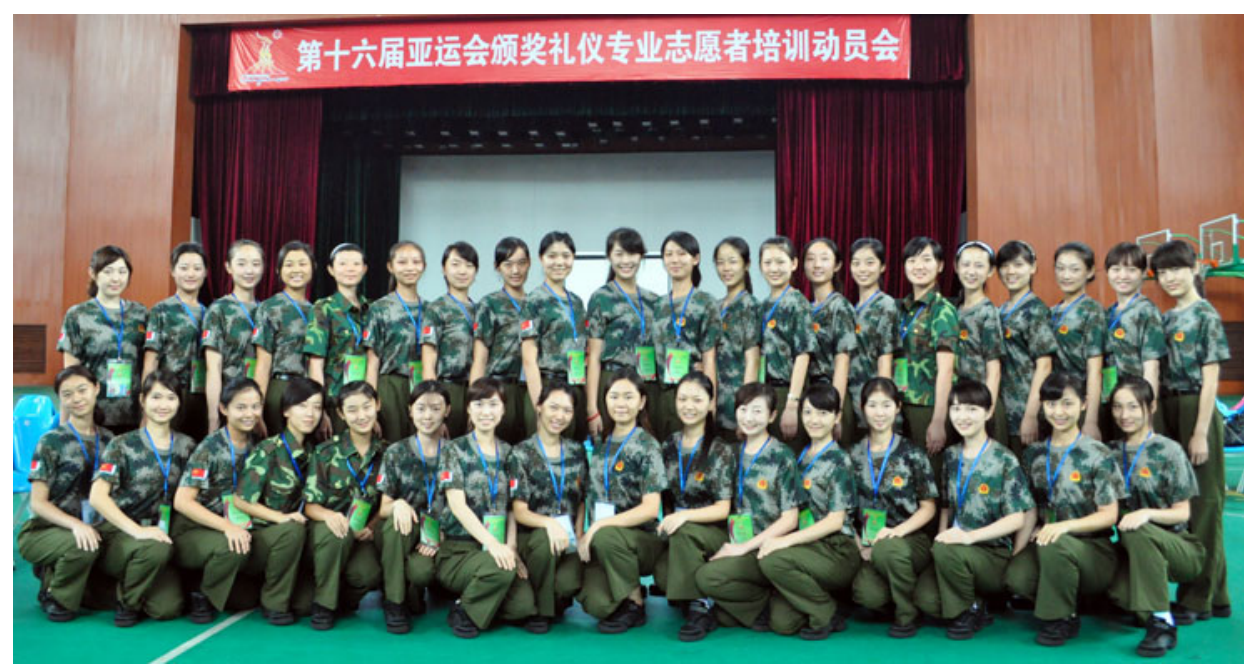

Figure 2. Ceremonial volunteers pose for a group photo at the end of the military training camp before the Guangzhou Asian Games. Photo courtesy of Miss Wang.

at many universities (see figure 2). ${ }^{3}$ Another is mass calisthenics, which is a daily sport exercise many Chinese students practice in schools.

\section{Etiquette Performance and Sports}

The thirteen young women I interviewed said that the most memorable moment for them serving in the games was maintaining the prescribed standing postures on stage and putting on the standard smile while holding the trays on which many metal medals were placed (as many as a dozen of them in the case of group presentations) for as long as an hour. In a tight qipao and high heels, it was a moment of high pressure for them. All took very seriously the idea that the condition of the team is equated with the nation's image. They were anxious that someone might deviate from the ideal posture or fall out of line. They believed that if the line were to fall apart, it would hurt the nation's reputation. Every single ceremonial volunteer I spoke with repeated, "I cannot make the nation lose face" (wo buneng gei guojia diulian). They also linked their unified movements to upholding a sense of national virtue and pride. Much like national athletes, ceremonial volunteers truly embody the status, shame, and reputation of the nation.

Indeed, from the training to being "on stage," ceremonial volunteers are not supposed to create a self that stands out as unique. Their training is not provided for

\footnotetext{
${ }^{3}$ Quite a few mainland Chinese students shared their experience of practicing mass calisthenics and thought it was a significant way the school cultivates a sense of collectivity and nationalist commitment at the daily institutional level. Another method is the military camp that is compulsory for many college freshmen, begun after the 1989 Tiananmen Student Democratic Movement. A few ceremonial hostesses told me that all students had to go through military training when entering college. They therefore did not find it special that the etiquette training also requires the same kind of training.
} 
candidates to appear in a beauty pageant, but to demonstrate a set of professionally prescribed movements collectively. Their aim is never to compete to be the most beautiful, or to draw attention to one's best presentation. As a team in ceremonial service, however, volunteers perform much more than just an attentive presence. In particular, they turn the daily bodily practice of everyday life_-smiling, walking, and standing-into a performance. They make their smiles amiable, their standing spirited, and their walk graceful. In the broader context of sport games, ceremonial service is in many ways part and parcel of the display of the national body, in which the individual bodies of young athletes and citizens are linked with the national character and building of the nation (Tomlinson and Young 2006).

Sport events celebrating the body and physical culture have long been driven by political and ideological motives, in both Western and non-Western societies (Tomlinson and Young 2006, 1). Gymnastics, for instance, was a well-known representation of the Aryan racial spirit in the form of mass rallies to express military discipline and the popular endorsement of the dictatorship in Nazi Germany. Gymnastics in Eastern Europe were a major means with which the new socialist nations linked body-training sports and young people to the nineteenth-century revolutionary movements of democracy, equality, and national renewal. Symbolizing unity, collectivity, and equality, sports of the masses such as gymnastics and mass calisthenics have always played a major role in the building of the new socialist culture in the Soviet Union. Petr Roubal (2003, 14), who studied gymnastics and the mass of display of bodies under communism as an ideal symbolic system, said, "the strong, beautiful and young bodies of the gymnastic displays under communism were testimony to the strength, beauty and youth of communist society in its entirety."

The sport of body training has an equally important role in the history of the People's Republic of China. During the Maoist period, shows of mass calisthenics were accompanied by slogans such as "uphold the revolutionary torch," "the People's Commune is great," and "expressing people's passion for and aspirations on behalf of the nation" (Chen, Lu, and Li 1990, 631). Gymnastics were a popular exercise promoted in many state-owned enterprises and in the People's Commune to express the positive feeling of community and social solidarity, class struggle, and the power of the proletariat (Roubal 2003, 4). The "broadcast gymnastics" (guangbo ticao) were an ingenious Maoist invention that deployed broadcasted music to mobilize the masses into collective exercise, with "the aim of training people's physical health for the national economy, development and defense" (610). Lu (2011) calls the broadcast gymnastics a "national collective ritual" because they were the most effective means of enabling an immediate-albeit ephemeral-feeling of equality among citizens across differences of sex, status, and class in a public space. In today's China, when young students move and dance in mass calisthenics expressing themes of great aspiration, their coordinated movements demonstrate "an example par excellence of the synchronization of the rhythms of the social body” (Brownell 1995, 146).

In this historical context of sport events, ceremonial volunteers' bodily performance is not just a form of service, but part of a bigger training and performance to strengthen the nationalist spirits of collectivity and uniformity. Through a series of mass-mediated recruitments, trainings, and displays of ceremonial volunteers' performances, the state includes the younger generation in the making of the ideal national social body, while effectively 
synchronizing their bodies with the collective one. Etiquette classes and volunteering programs are a more effective and appealing way to actualize the national body ideal.

\section{Conclusion}

The figure of the ceremonial volunteer represents a new state effort to engineer a new woman citizen, incorporating diverse gender discourses and practices. Combining both a cultural-nationalist ideal of femininity and the Maoist appeal to free and strong womanhood, the ceremonial volunteer is simultaneously elegant, disciplined, militarized, and dedicated to serving national collective interests. The strategy of combining ceremonial services and volunteer services has been very effective. It appeals greatly to college women students, who are self-motivated in terms of serving some broader social purpose, and who want to actualize themselves through participating in grand events. Lastly, both the use of strict bodily discipline in volunteer training and the presence of volunteers in military parades suggest that the volunteer program in China does not automatically mean a technique of governmentality that is decentralized and self-sustaining. In fact, volunteer initiatives can also be a major means for the communist party-state to resuscitate the collectivist and military rituals, values and narratives of the Maoist era.

Ceremonial volunteers are active agents negotiating their way through competing discourses and practices. Although all are proud of joining the training, they do not necessarily conform to the values and ideals embedded in the training lessons. Some think of it as free etiquette training to strengthen their portfolios for future career development. Several interviewees insisted that their participation was solely about getting a passport to the grand event. While most regard it a great experience and are happy to enact the nationalist bodily ideals and patriotic ideology as volunteers, some have reservations about its arrangements, especially the design of the dress uniform. The Guangzhou participants, for instance, were not very happy about their dress uniform during the Asian Games in 2010, as it raised the controversy of objectifying women's bodies. Entitled "passing clouds and flowing water" (xingyun liushui), the outfit was designed to communicate the culture of freedom and flexibility in southern China. Its ultra-thin swimwear material, however, resulted in a see-through effect, which excessively revealed the wearers' bodily shapes, including the shapes of their pelvic bones. Various media captured how male guests and male athletes fixed their gaze on the tightly wrapped bodies and, often, buttocks of the volunteers on stage. The gazing caused much controversy and questions over whether the uniform was appropriate (Renren.com 2010). A Chinese sport website ran a feature entitled "Who was pissed off by "passing clouds and flowing water?" and included news reports from Korea that athletes felt "provoked" by the thinly dressed volunteers (Wangyi Yayun 2010). Netizens widely criticized the design as indecent. Some went so far as to critique the design as "making the volunteers look like nightclub girls" (Wangyi Yayun 2010). When asked about such public outcry, my informants did not elaborate much. All said that the dress was too tight and many recalled having starved through the morning in order to look good in it. Sally was the only interviewee bold enough to blame the dress as "sexualizing women" (xinghua nvxing). She recalled an embarrassing incident of a male audience member who photographed the buttocks of her team members; he was taken away by security for his actions. 
The incident reveals the tension and challenge in the state's effort to promote the model women citizens who are nice-looking and dedicated. On the one hand, the training coach I talked with emphasized the concept of a "healthy beauty," which is related to the idea of modern femininity achieved through sport training and physical strength (You 2003). In fact, individual coaches have tried to ensure that the images of these girls do not easily fit into the stereotype of self-Orientalizing female figures. On the other hand, the way these volunteers are dressed to accentuate their feminine body has inevitably made them targets of the male gaze, or more broadly, targets of visual pleasure (Mulvey 1975). The unintended controversy over their uniforms reveals that the new mode of volunteer mobilization can also be complicit in dominant gender ideology, which commodifies and sexualizes women's bodies, youth, and beauty. It also undermines the making of a new socialist person who is reinscribed with gender and class differences. Lastly, if the original idea of having women volunteers go through intense physical training is to promote a dedicated and patriotic citizenry, their classy, even sexy, uniforms ultimately expose the many contradictory drives and discourses in such a mobilization effort.

There is much discussion about the rise of China as a powerful political and economic player in global capitalism. This essay contributes to the broader debate and understanding of how the Chinese state cultivates cultural and national identity in the context of its rise. I am not suggesting that the ceremonial volunteer is the only form of citizen in the making. The Chinese state will surely continue to modify her image and experiment with other forms of citizen-making. Despite the fact that extensive media coverage and public discussions have subsided after the mega events discussed here, the figure of the ceremonial volunteer has become even more popular such that one can see her serving at many kinds of official business and government events. How such state-endorsed images of model women citizens continues to change and transform everyday life will be vital in understanding public culture in China.

\section{Acknowledgments}

The South China Research Center and the Faculty of Arts at the Chinese University of Hong Kong provided funding support for this research. I thank Lisa Rofel, Sealing Cheng, the three anonymous reviewers, and Jeffrey Wasserstrom for helpful comments at various stages of the essay. I am also thankful for Chen Wenyan for years of research assistance.

\section{List of References}

Anderson, Benedict. 1991. Imagined Communities: Reflections on the Origin and Spread of Nationalism. New York: Verso.

BAIDU.COM. 2015. "Liyizhibang ciyujieshi" [Liyizhibang: The meaning of the phrase]. http:// baike.baidu.com/subview/48502/11094921.htm (accessed November 11, 2017).

. 2017. "Shenme shi dongfangmei" [What is Oriental beauty?]. September 19. https://zhidao.baidu.com/question/98464486.html (accessed November 11, 2017).

Balogun, Oluwakemi M. 2012. "Cultural and Cosmopolitan: Idealized Femininity and Embodied Nationalism in Nigerian Beauty Pageants.” Gender b Society 26(3):357-81. 
Barlow, TANi. 1995. “Theorizing Woman: Funu, Guojia, Jiating.” In Body, Subject and Power in China, eds. Angela Zito and Tani Barlow, 253-90. Chicago: University of Chicago Press.

Browneld, Susan. 1995. Training the Body for China: Sports in the Moral Order of the People's Republic. Chicago: University of Chicago Press.

—. 1998. "The Body and the Beautiful in Chinese Nationalism: Sportswomen and Fashion Models in the Reform Era." China Information 13(2-3):36-58.

Chatterjee, Partha. 1986. Nationalist Thought and the Colonial World: A Derivative Discourse. London: Zed.

Chen, Zhenhua, Enchun Lu, and Shiming Li. 1990. Zhongguo ticao yundong shi [History of gymnastics in China]. Wuhan: Wuhan chubanshe.

Chew, Matthew. 2007. "Contemporary Re-emergence of the Qipao: Political Nationalism, Cultural Production and Popular Consumption of a Traditional Chinese Dress." China Quarterly 189:144-61.

CHINA.COM.CN. 2008. "Yayun liyi xiaojie chiliang biaozhunbubiaozhun, guanfang biaozhun chulu” [Official rules on Beijing Olympics' ceremonial volunteers' qualities]. February 20. http://big5.china.com.cn/culture/txt/2008-02/20/content_10271330.htm (accessed November 11, 2017).

Chong, Gladys Pak Lei. 2011. "Volunteers as the 'New' Model Citizens: Governing Citizens through Soft Power." China Information 25(1):33-59.

Creak, Simon. 2015. Embodied Nation: Sport, Masculinity and the Making of Modern Laos. Honolulu: University of Hawai'i Press.

Feng, Youlan. 1985. Zhongguo zhexue jianshi [A short history of Chinese philosophy]. Translated by Tu Youguang. Beijing: Beijing University Press.

Fleischer, Friederike. 2011. "Technology of Self, Technology of Power: Volunteering as Encounter in Guangzhou, China.” Ethnos: Journal of Anthropology 76(3):300-325.

Gilmartin, Christina K. 1995. Engendering the Chinese Revolution: Radical Women, Communist Politics, and Mass Movements in the 1920s. Berkeley: University of California Press.

Gilmartin, Christina K., Gail Hershatter, Lisa Rofel, and Tyrene White, eds. 1994. Engendering China: Women, Culture, and the State. Harvard Contemporary China Series No. 10. Cambridge, Mass.: Harvard University Press.

GLOBAL TIMES. 2015. "Nvliyibing lihongzhuang, jinguo burang xumei yeyao meimeida" [Female soldiers in the grand military parade]. Chinaso.com, September 3. http:// law.chinaso.com/detail/20150903/1000200032711721441240615307136593_1.html (accessed November 11, 2017).

Hanser, Amy. 2008. Service Encounters: Class, Gender, and the Market for Social Distinction in Urban China. Stanford, Calif.: Stanford University Press.

He Meng. 2010. "Zhao Na: Kengqiang meigui zhanfang yuebing zhilu” [Zhao Na’s experience in a military parade]. People.com.cn, May 20. http://stu.people.com.cn/GB/ 186922/11650531.html (accessed November 11, 2017).

Heng, Geraldine, and Janadas Devan. 1992. "State Fatherhood: The Politics of Sexuality, Nationalism and Race in Singapore." In Nationalisms and Sexualities, eds. Andrew Parker et al., 343-64. New York: Routledge.

Hoffman, Lisa. 2013. "Decentralization as a Mode of Governing the Urban in China: Reforms in Welfare Provisioning and the Rise of Volunteerism." Pacific Affairs 86 (4):835-55.

Jin Yinong. 2006. "Rethinking the 'Iron Girls': Gender and Labor during the Chinese Cultural Revolution.” Translated by Kimberley Ens Manning and Lianyun Chu. Gender and History 18(3):613-34. 
Joo, Rachael Miyung. 2012. Transnational Sport: Gender, Media, and Global Korea. Durham, N.C.: Duke University Press.

Kim, Elaine, and Chungmoo Choi. 1997. Dangerous Women: Gender and Korean Nationalism. New York: Routledge.

LAN XIAOWEI. 2008. “Aoyun liyixiaojie yaokuaizi xueweixiao” [Olympics ceremonial volunteers learn to smile by biting chopsticks]. United Daily News, January 10. http://mag. udn.com/mag/world/printpage.jsp?f_ART_ID=105847 (accessed October 4, 2009).

Liberation Army News. 2009. "Yuebing nvbingtuan lingren yanqianyiliang" [People are amazed at the militia women's team]. Xinhuanet, October 2. http://news.xinhuanet.com/school/2009-10/02/content_12172001.htm (accessed June 4, 2016).

Lu Yunting. 2011. "Shenti de jituan yishi: Zuowei quanli, dongzuo he wuqu de guangbo ticao" [Organizational ritual of the body: Broadcast gymnastics as rights, activity, and misunderstanding]. Tiyu yu kexue 32(1):24-30.

McClintock, Anne. 1995. Imperial Leather: Race, Gender and Sexuality in the Colonial Contest. New York: Routledge.

Mohanty, Chandra Talpade. 2003. Feminism without Borders: Decolonizing Theory, Practicing Solidarity. Durham, N.C.: Duke University Press.

Mosse, Geonge. 1998. Nationalism and Sexuality: Middle-Class Morality and Sexual Norms in Modern Europe. Madison: University of Wisconsin Press.

Mulvey, Laura. 1975. "Visual Pleasure and Narrative Cinema." Screen 16(3):6-18.

Ong, Ainwa, and Michael G. Peletz. 1995. "Introduction to Bewitching Women, Pious Men: Gender and Body Politics." In Gender and Body Politics in Southeast Asia, eds. Aihwa Ong and Michael G. Peletz, 1-18. Berkeley: University of California Press.

Parker, Andrew, Mary Russo, Doris Sommer, and Patricia Yaeger, eds. 1992. Nationalisms and Sexualities. New York: Routledge.

PEOPLE.CN. 2015. "Liyi xiaojie beizhan lianghui, shuangtui jia baizhi budiu dishang" [Miss Etiquette trained for the two meetings, papers kept in between legs]. March 2 . http://finance.people.com.cn/n/2015/0302/c1004-26621342.html (accessed June 4, 2016).

Qin Jianzhong. 2008. "Women cong liyi xiaojie de zishi li duchu le shenme" [What we can learn from Miss Liyi’s posture]. Caijing.com.cn, August 16. http://corp.caijing.com. cn/2008-08-16/110011749.html (accessed November 11, 2017).

RENREN.COM. 2010. "Beijing fuzhuang xueyuan sheji de yayun liyi fuzhuang tai xinggan re zhengyi” [Asian Games etiquette outfit designed by Beijing Apparel Design Institute too sexy and controversial]. November 22. http://blog.renren.com/share/201805820/ 4221808794 (accessed November 11, 2017).

Reuters and Agence France-Presse. 2014. "North Korea Softens Fiery Rhetoric with Promise to Send Cheerleaders to South." South China Morning Post, July 7. http://www.scmp.com/news/asia/article/1548573/north-korea-softens-fiery-rhetoricpromise-send-cheerleaders-south?comment-sort=recommended\&edition=international (accessed June 4, 2016).

Rofel, Lisa. 1999. The Other Modernities: Gendered Yearnings in China after Socialism. Berkeley: University of California Press.

Roubal, Petr. 2003. "Politics of Gymnastics: Mass Gymnastics Displays under Communism in Central and Eastern Europe." Body and Society 9(2):1-25.

Seth, Sanjay. 2013. "Nationalism, Modernity, and the 'Woman Question' in India and China." Journal of Asian Studies 72(2):273-97. 
Stoler, Ann L. 1995. Race and the Education of Desire: Foucault's History of Sexuality and the Colonial Order of Things. Durham, N.C.: Duke University Press.

Tomlinson, Alan, and Christopher Young. 2006. "Culture, Politics, and Spectacle in the Global Sports Event: An Introduction.” In National Identity and Global Sports Events: Culture, Politics, and Spectacle in the Olympics and the Football World Cup, eds. Alan Tomlinson and Christopher Young, 1-14. Albany: State University of New York Press.

Wang Di, Yang Qingmin, and Ji Zhenfeng. 2009. "Chaoyangqu jingying: nvbing xunlian baodao" [Elites in Chaoyang (District): Female militia report duty to training]. Xinhua News, September 28. http://chn.chinamil.com.cn/zt/2009yuebinzt/2009-09/ 28/content_4051181.htm (accessed June 4, 2016).

Wangy YAYun. 2010. "Xingyunliushui reshuile?” [Who was pissed off by “passing clouds and flowing water?"]. 163.com, November 19. http://2010.163.com/special/xingyunliushui/ (accessed November 11, 2017).

XINHUANET.COM. 2009. "Nvbingfangdui lingren yanqianyiliang" [People are amazed at the militia women's team]. October 2. http://news.xinhuanet.com/politics/2009-10/02/ content_12172162_1.htm (accessed June 4, 2016).

Xue, Mike. 2009. "China 60th Anniversary Parade-Women's Army HD (Subbed)." YouTube, October 1. https://www.youtube.com/watch?v=iG3dPnD1SGo (accessed October 28, 2017).

Yan, Grace, and Carla Almeida Santos. 2009. "China Forever': Tourism Discourse and Self-Orientalism.” Annals of Tourism Research 36(2):295-315.

YAnG, JiE. 2011. "Nennu and Shunu: Gender, Body Politics, and the Beauty Economy in China." Signs: Journal of Women in Culture and Society 36(2):333-57.

YAng, Mayfair Mei-hui. 1999. "From Gender Erasure to Gender Difference: State Feminism, Consumer Sexuality, and Women's Public Sphere in China.” In Spaces of Their Own: Women's Public Sphere in Transnational China, ed. Mayfair Mei-hui Yang, 1-35. Minneapolis: University of Minnesota Press.

You Jianming. 2003. Jindai Zhongguo nuzi jianmei de lunshu (1920-1940) [The discourse of healthy beauty among modern Chinese women (1920-1940)]. Taiwan: Institute of Modern History, Academia Sinica.

Yuval-Davis, Nira. 1997. Gender and Nation. London: Sage.

Zheng, Tiantian. 2009. Red Lights: The Lives of Sex Workers in Postsocialist China. Minneapolis: University of Minnesota Press.

Zhongtian News. 2015. "Lianghui liyi xiaojie peixun, tui jia zhi budiaodi" [Posture training for the Miss Etiquette at the two meetings: Keep a piece of paper in between your knees]. YouTube, March 2. https://www.youtube.com/watch?v=I19n4jCyg5k (accessed November 11, 2017).

Zito, Angela. 1995. "Silk and Skin: Significant Boundaries.” In Body, Subject and Power in China, eds. Angela Zito and Tani Barlow, 103-30. Chicago: University of Chicago Press. 